\title{
Developing Impact Monitoring within District Administrations
}

\section{John Watson}

There is considerable interest at the moment in impact monitoring: that is, measurement of the effect of development programmes during implementation rather than (as is of ten the case) after they have come to an end. The measurement of impact is usually assumed to be a task for evaluators from outside the programme; not only are they more likely to have the appropriate resources, they are also believed to be relatively free from bias. However, a case can be made for establishing within a project or programme the capacity to carry out its own monitoring. How this might be organised, and what measurement procedures might be used, seem worthwhile questions for investigation; this paper suggests one possible line of approach. It draws upon the author's experience in India, but may be of relevance elsewhere.

There are several reasons why impact monitoring has become important. These are:

-the apparent failure of the 'trickle-down' approach; that is, the belief that investment or institutional change affecting the more accessible (and often richer) groups in rural society will ultimately benefit the poorer and harder to reach. Arguing that it does matter where and to whom investment goes means establishing that it is actually getting there. This has probably contributed to:

-increasing emphasis in government policy-making on 'social justice'; the belief that development should bring about greater equity within society;

- a movement, by no means deliberate but quite perceptible, away from 'master planning' and towards continuous or recursive planning; in effect, the rejection of the notion of the plan as a fixed and unalterable document. In India's special schemes at least, the annual plan of each department is assumed to be based upon a review of progress subject to the framework of a long term strategic plan. Reviewing progress and modifying programmes accordingly supposes some measure of outcomes, directly or through proxy measures;

-decentralisation; and especially the protracted emergence of the district as the level at which detailed planning should be done (Government of India, 1978: 7).

Decentralisation has several consequences for district administrators and departmental staff. Planning is choice; and planning at district level means the allocation of resources among different areas, often in the face of competing political claims; allocation too between departmental programmes. This imposes a load upon the districts which they are usually ill-equipped to meet. They lack trained planning staff, the problem which stimulated the Indian Institute of Public Administration's coordinated project for the establishment of district planning cells. They have to make choices too within an administrative tradition in which departments have a great deal of independence in determining their work programmes. Those that do the planning need some means of justifying within the district the allocative choices they make; they may also be under a certain amount of pressure to demonstrate to politicians and government that they are meeting the economic and social objectives of current policy.

The immediate problem is that the indicators used at present are of limited value in meeting these needs. This is illustrated by Anantapur; one of the six district level Drought Prone Area Projects financed by the IBRD in India (see Sandford, 1978). DPAP is a target group-oriented area programme, aimed at small farmers (usually defined by the area of land they own) and landless labourers through direct investment and subsidy.

The project's components-soil conservation work, the construction of irrigation wells, the establishment of grazier cooperatives and so onare relatively orthodox in design, and indeed in some cases already undertaken as a routine part of the work of the departments. They are, however, identifiably separate; financed by a specific allocation, restricted to the drought-prone areas of the district, aimed at target groups and coordinated by a small project management team. There is a strategic plan; within the framework of this, each department prepares an estimate for the year's work, which is approved by a district level committee. The committee has the task of reviewing progress, and recommending where necessary modifications of the programmes-which predicates some form of monitoring within the district. 
At the moment, the Anantapur project uses three indicators (see DPAP Project Administration, 1976):

-expenditure: with particular emphasis on the reporting of under- and over-spending of the annual allocation for each programme;

-physical achievement: measures of the actual physical progress of each programme-for example, the number of hectares contour bunded or the number of grazier cooperatives formed;

-beneficiary count: the number of farmers in each target group who have received subsidy.

If we characterise the rural economy as the "black box' of physics-that is to say, certain inputs into the box (whose workings are unknown) generate outputs, then the first two indicators are input measures; the third is an incidence measure, identifying who has received support, but not what they have done with it. There is no direct attempt to measure outputs; rather the assumption is made that the measures, taken together, are eff ective proxies for output.

It is not difficult to hypothesise what kind of improved indicators might be used, if measurement were possible. They could include improved measures of incidence, and perhaps particularly the spatial incidence of measures throughout the district. ${ }^{1}$ They could include specific impact indicators, attempting to measure direct outputsemployment, production or incomes. They might include measures of long-term change, in the environment or in society: water table levels, soil erosion or income distribution, landlessness, rural indebtedness.

A conventional approach on the part of external investigators (and by 'external' I mean those who, within district perception, come from outside the district, whether from government or elsewhere-the reason for this distinction will become clear) might involve:

-the selection of potential indicators;

- the design of measurement procedures;

- the testing of such procedures, probably using the investigators' own resources but presumably with the active collaboration of the district's staff.

The indicators might be formal: the modification and development of the data collection methods

1 Dr Waheeduddin Khan, of the Administrative Staff College of India in Hyderabad, is currently working on such measures. currently employed by the departments; the crop cutting surveys, say, which are currently used in India to estimate average yield. Or they might be informal: especially the use of rapid appraisal methods, sample surveys or field meetings with beneficiaries. The ultimate aim would be a series of recommendations for use by the district, in form ranging from monograph to manual.

However, there are a number of difficulties inherent in the conventional method. Firstly, it is singularly difficult to predict how far improved monitoring can actually be implemented in the sense of incorporating procedures as a matter of routine into the work of a department. Unless we are bent on organisational reform, the procedures have to fit the machine as it is; field level staff must be able to collect the information without prejudice to their other tasks, and, more important, in the absence of any special pressure to perform the task. The methods used to aggregate and analyse the information have to be recognisable to those who have to transmit the information (in the sense of a junior officer preparing a report) and to those who have to act upon it.

More important perhaps, is the question of the extent to which district staff are prepared to adopt improved procedures. $A$ number of pressures, which stem from the ways in which district administrations are organised and perceive their roles, hinder the adoption of innovations even where these have been shown to be useful and feasible. Monitoring is not a riskfree process; the measurement of the impact of a departmental programme has considerable implications for the staff responsible for it. The steering of resources towards the relatively effective components of a programme, year by year, bears upon departmental budgets, departmental claims upon staff, accommodation and other resources and, perhaps most significantly, upon reputation vis-à-vis peers in the district and its superiors elsewhere. One advantage of input indicators, and perhaps especially expenditure; is that it is relatively easy to adjust the rate of spending to meet financial targets even at the cost of overall effectiveness. Srivastava offers a nice example from the DPAP programme in Jhabua district, Madhya Pradesh:

"it was observed that the Executive Engineers had proposed a much larger number of irrigation projects (tanks) than could be justified on the basis of annual allocations. This fact was explained .... it is much easier to spend or 
absorb large financial allocations where there is a number of incomplete projects" (1978: 24).

It is clearly much more difficult to respond to the signals of output indicators.

Other pressures are more difficult to identify. A considerable quantity of evaluation research is done in India, or varying quality; much of it commissioned by the government and ostensibly directed towards administrative improvement. In discussing this research, it is difficult to avoid the sense that district staff perceive much external work as 'academic'; produced, that is, without any real knowledge of the constraints that exist at district level.

Whether this is so or not, it is the perception that governs the response. More important, there may be no established procedure for adopting innovations where these stem from an externally produced study. District administrative or departmental staff may be unwilling to assume the responsibility of implementing them directly though well aware of them; and, at higher levels, there may be few clear lines of communication and control which convert recommendations for change into clear unambiguous instructions for the modification of operating procedures.

With these problems in mind, the DAG is currently considering a means of investigation which will give district staff a major role in reforming monitoring procedures. It is clearly coloured by recent experience in Khartoum (see Curtis' article). Thinking at the moment envisages the following line of approach. Firstly, the use of a small team, perhaps staffed in collaboration with other institutes, which will attempt to identify a number of improved indicators and their associated measurement procedures. This will then constitute the material for two conferences - or workshops - held within a district and bringing together staff drawn from the district administration and the technical departments. The first conference would examine the proposals for change, fitting them to the resources known to be available in the district, and developing them to the point of procedural recommendations. A period would follow in which departmental members would attempt to implement the recommendations in their routine work; using the second conference to report and codify their experience.

A number of issues need further exploration, and particularly the logistics and timing of conferences within a district. Nor will such conferences necessarily solve the problems of bias and non-aversion that are likely to modulate departmental responses. Nevertheless, it does does seem likely to make a contribution to developing practical procedures which will at the same time seem legitimate innovations in district perception.

\section{References}

Government of India, Planning Commission, 1978, Report of the working group on block level planning, Government Press, New Delhi

DPAP Project Administration, 1976, Brochure on the implementation of drought prone areas programme in Anantapur district, Anantapur

Sandford, Stephen, 1978, "Some aspects of livestock development in India, part 1: Indian background", ODI Pastoral Network Paper 5C, London

U.K. Srivastava, 1978, Management of drought prone areas programme; analysis and case studies from Jhabua district, Abhinav publications, New Delhi 


\section{Books Received}

Roberto Cuca and Catherine S. Pierce, Experiments in Family Planning, The Johns Hopkins University Press, USA, 1978

W. Andrew Axline, Caribbean Integration, Nichols Publishing Company, New York, 1979

K. D. Sharma and M. A. Qureshi (eds.), Science, Technology and Development, Sterling Publishers PUT Ltd., New Delhi, 1978

M. Abdurrahman and P. Canham, The Ink of the Scholar, Macmillan Nigeria Publishers Ltd., Ibadan, 1978

Dr. Humberto Nagera, Basic Psychoanalytic Concepts on Metapsychology, Conflicts, Anxiety and Other Subjects, The Hampstead Clinic Psychoanalytic Library, Vol. IV, George Allen and Unwin Ltd., London, 1970

Wim Dierckxsens, Capitalismo y Problacion, Editorial Universitaria Centro Americana (EDUCA), Costa Rica, 1979
The Indian Journal of Social Work, Vol. XXXIX, No. 3, Tata Institute of Social Sciences, Bombay, October 1978

Integration, No. 10, Revue du CMERA, Le Centre Maghrebin d'Etudes et de Recherches Administratives, Alger, 1978

Itinerario, No. 2, Leyden Centre for the History of European Expansion, Leyden University, the Netherlands, 1977, 1978

Francine R. Frankel, India's Political Economy, 1947-1977, Princeton University Press, New Jersey, 1979

Peter Gutkind, Bibliography on Unemployment, with Special Reference to Africa, Centre for Developing Area Studies, Montreal, 1978

Sartay Ayiz, Chinese Rural Development, Macmillan, 1978 